\title{
Globe
}

Revue internationale d'études québécoises

\section{André Lamontagne : Le roman québécois contemporain. Les voix sous les mots. Montréal, Fides, coll. " Nouvelles études québécoises », 2004}

\section{Viviane Asselin}

Volume 8, numéro 2, 2005

URI : https://id.erudit.org/iderudit/1000922ar

DOI : https://doi.org/10.7202/1000922ar

Aller au sommaire du numéro

Éditeur(s)

Globe, Revue internationale d'études québécoises

ISSN

1481-5869 (imprimé)

1923-8231 (numérique)

Découvrir la revue

Citer ce compte rendu

Asselin, V. (2005). Compte rendu de [André Lamontagne : Le roman québécois contemporain. Les voix sous les mots. Montréal, Fides, coll. « Nouvelles études québécoises ", 2004]. Globe, 8(2), 310-314. https://doi.org/10.7202/1000922ar d'utilisation que vous pouvez consulter en ligne.

https://apropos.erudit.org/fr/usagers/politique-dutilisation/ 
essentielle. Toute considération sur la langue doit donner lieu à de " délicats équilibres " et à de " discrètes épiphanies ", écrit l'auteur dans les dernières lignes de l'ouvrage. Cette contingence lumineuse, éclairant toute une époque, lui aura permis de comprendre le sujet de la langue au Québec en préservant son essentielle dignité et sa modernité.

François Paré University of Waterloo

\section{André Lamontagne}

Le roman québécois contemporain.

Les voix sous les mots.

Montréal, Fides, coll. "Nouvelles études québécoises ", 2004.

Où en est le roman québécois? Quelle est sa situation, sa valeur? Qu'est-ce qui l'habite, l'occupe, le secoue, le hante ? En quoi se distinguet-il ? Bref, comment se porte la littérature québécoise contemporaine ? La question est 'certes d'actualité, mais le manque de recul exige une certaine prudence à l'égard des jugements prononcés. Peut-être est-ce d'ailleurs la raison pour laquelle, depuis 1980 , la critique se contente généralement de souligner la diversité de la production romanesque : s'il existe un quelconque dénominateur commun, c'est celui de l'hétérogénéité. Autrement, le roman québécois résiste à toute catégorisation. Pourtant, aussi kaléidoscopique qu'apparaisse le panorama littéraire québécois, il semble que ce soit là éviter de plonger trop en avant dans le débat. Qu'il y règne la disparité, certes - c'est le lot de toute littérature contemporaine dont on comprend encore difficilement les enjeux-, mais qu'il ne s'y exprime aucune préoccupation ou esthétique communes, la chose parait peu probable.

Aussi le vent tend-il à changer. Avec le $\mathrm{xxI}^{\mathrm{e}}$ siècle vient le temps des bilans - et des prédictions. Des critiques littéraires osent régulièrement quelque tentative de classification. Des colloques témoignent de l'intérêt de et à l'égard de la production récente. Des ouvrages d'envergure sont publiés, chacun saisissant la littérature contemporaine par un trait récurrent et définitoire - Roseline Tremblay poursuit le travail d'Ảndré Belleau 
en abordant le personnage écrivain (2004); René Audet et Andrée Mercier dirigent un collectif sur les enjeux de la narrativité contemporaine (2004); Hans-Jürgen Greif, en collaboration avec François Ouellet, brosse une brève rétrospective du genre romanesque depuis 1960 (2004), de sorte qu'à partir des quelques travaux sur la littérature contemporaine se dresse un portrait forcément fragmentaire, mais néanmoins appréciable du paysage littéraire québécois actuel.

Le dernier ouvrage d'André Lamontagne participe de ce mouvement, en appréhendant pour sa part la production romanesque québécoise contemporaine par la question de l'intertextualité. L'auteur convient d'emblée que celle-ci occupe le roman québécois depuis Le chercheur de trésors ou l'influence d'un livre de Philippe Aubert de Gaspé (1837) ; seulement, ses paramètres d'usage se sont modifiés corrélativement à l'autonomisation et à la reconnaissance de la littérature québécoise. De fait, la pratique intertextuelle a longtemps constitué une stratégie de légitimation littéraire: l'intertexte français agissait alors comme justification et comme garantie de la valeur esthétique de l'œuvre. Cela dit, si les écrivains du $\mathrm{xIX}^{\mathrm{e}}$ siècle et de la première moitié du $\mathrm{xx}^{\mathrm{e}}$ siècle respectent le style normatif de la France, ils ne contribuent pas moins à la formation d'une littérature nationale. Sous l'influence messianique de l'abbé Casgrain, ils campent leurs événements romanesques dans un environnement socioculturel canadien-français: d'où le "conflit des codes " - l'expression est d'André Belleau, avec qui Lamontagne avoue sa filiation - qui caractérise le roman des années 1940 et 1950 : le canon littéraire français, qui se déploie uniquement sur le plan discursif, se frotte à un cadre diégétique canadien-français, marqué par "l'inné, l'authenticité et une méfiance à l'égard de la culture " (p. 12). L'affirmation d'une identité propre se voit donc empêchée par une recherche de légitimité institutionnelle. Les écrivains de l'époque sont tenus de se (nous) dire avec les moyens d'autrui.

Toutefois, Lamontagne constate que, depuis 1970 et à plus forte raison depuis 1980, l'heure n'est plus au conflit. La trajectoire intertextuelle connaît deux changements majeurs, pour beaucoup liés à la percée du roman québécois sur la scène internationale. D'une part, l'intertextualité gagne en maturité en délaissant la seule dimension énonciative pour investir la trame diégétique. C'est dire que les références convoquées jouent moins sur les valeurs symboliques et institutionnelles que sur le fonctionnement et le déroulement mêmes du récit. Les intertextes 
balzaciens d'Un bomme et son péché de Claude-Henri Grignon (1933), s'ils signalent les influences de l'auteur et autorisent son entreprise, exercent somme toute une fonction ornementale. Au contraire, l'intertextualité présente dans la fiction des deux dernières décennies agit sur les lignes pragmatiques et actorielles du récit, signe que "l'art du recyclage " a progressé. Il est donc possible, et c'est là l'ambition poursuivie par Lamontagne, de tracer l'évolution du roman québécois contemporain sous la loupe intertextuelle. L'autre inflexion que connaî l'activité intertextuelle récente concerne la diversification des sources d'emprunt. Les références internationales - bibliques, coraniques, grecques, latinoaméricaines, mais surtout états-uniennes, et plus encore québécoises disputent désormais l'hégémonie française.

On pourrait certes y voir la marque du postmodernisme - il s'agit d'ailleurs de l'orientation qu'empruntent la plupart des ouvrages sur l'intertextualité contemporaine. Cependant, Lamontagne se garde bien de régler aussi expéditivement la question, ne serait-ce que parce qu'il vise précisément à cerner le caractère distinct du roman québécois dans le contexte globalisant du postmodernisme. D'où l'hypothèse défendue : la pratique intertextuelle québécoise est gouvernée par la problématique identitaire (on ne saurait y échapper) et son corollaire, la fascination pour l'Autre. Par là même, Lamontagne dépasse la seule dimension de l'intertextualité pour embrasser des préoccupations du discours théorique actuel. Il touche à la thématique de l'altérité qui, du fait qu'elle traverse la littérature québécoise depuis ses origines jusqu'à l'écriture migrante, fédère nombre d'études. L'auteur est également confronté aux écueils de la périodisation, au nébuleux passage du modernisme au postmodernisme, qui ne fait pas consensus chez les intellectuels. À ce propos, que plusieurs d'entre eux interrogent la pertinence et la justesse de désigner comme "postmoderne "l'époque contemporaine, allant même jusqu'à dénoncer l'insuffisance d'une telle étiquette, plus architecturale ou philosophique que littéraire, plus européenne ou étatsunienne que québécoise, Lamontagne paraît (feint de ?) l'ignorer. Il est vrai: que l'objet de son ouvrage n'est pas de débattre du caractère problématique du postmodernisme ; d'autres s'y engagent volontiers à sa place. Seulement, on peut lui reprocher d'utiliser cette acception avec trop de légèreté et d'admettre trop naturellement les prérogatives qui, semble-t-il, s'y rattachent. La crédibilité de l'auteur en souffre au passage. C'est d'autant plus dérangeant que l'ensemble de l'ouvrage s'articule pour beaucoup autour du postmodernisme. 
Cela dit, cette négligence est rachetée par la rigueur et la précision méthodologiques dont fait preuve Lamontagne dans l'analyse du corpus retenu. Celui-ci se compose de sept romans, qui représentent autant de moments charnières de l'évolution de la prose narrative québécoise : ainsi L'amélanchier de Jacques Ferron (1970), Don Quichotte de la Démanche de Victor-Lévy Beaulieu (1974), Maryse de Francine Noël (1983), La Québécoite de Régine Robin (1983), Comment faire l'amour avec un Nègre sans se fatiguer de Dany Laferrière (1985), La rage de Louis Hamelin (1989) et La tournée d'automne de Jacques Poulin (1993). Il est permis de penser que l'exhaustivité dont l'auteur témoigne dans chacune des études explique la faiblesse du nombre de romans abordés (mais l'excuse-t-elle ?). Force est de noter en effet que l'affranchissement de la littérature québécoise repose sur bien peu de choses, de sorte que l'on se demande si le corpus est suffisamment substantiel pour être représentatif de la mutation de la littérature québécoise depuis 1970. Certes, Lamontagne justifie le choix des sept œuvres par le fait qu'elles balisent l'histoire de la mémoire intertextuelle contemporaine. Mais en quoi les textes étudiés sont-ils "meilleurs " pour attester de l'émancipation du roman québécois, ceux d'un Réjean Ducharme, d'une Monique LaRue ou d'une Nicole Brossard, qui se méritent tout au plus une simple mention au passage?

Toujours est-il qu'une progression se dessine effectivement au fil des études menées par Lamontagne. Les stratégies intertextuelles se diversifient et se complexifient, mais demeurent surdéterminées par l'incontournable question identitaire et l'épreuve de l'altérité. Entre un Jacques Ferron qui convoque les contes pour enfants et la Genèse pour raconter la fondation d'un pays fantasmé ; une Francine Noël qui désacralise la littérature française au profit de la littérature du Québec et d'autres pays, marquant ainsi, de concert avec Régine Robin, la transition du modernisme au postmodernisme; et un Jacques Poulin qui assume sereinement son héritage québécois, avec sa part de francité et d'américanité, on voit se profiler une littérature québécoise devenue " un signe culturel, c'est-à-dire un objet suffisamment reconnaissable, dans notre société, pour tenir lieu de réalité et être incorporé à un roman * (p. 252). Chose certaine, les perspectives ont bien changé dans le quart de siècle qui suit 1960 , au gré du nationalisme et du postcolonialisme, du modernisme et du postmodernisme, de la déconstruction féministe et de l'écriture migrante. On ne peut qu'accuser la rapidité des mutations qui ont configuré le paysage littéraire québécois dans sa quête d'authenticité. Une 


\section{REVUE INTERNATIONALE D'ÉTUDES QUÉBÉCOISES}

preuve probante: le Poulin "intertextualisateur "se transforme, chez la jeune génération, en Poulin * intertextualisé *.

En terminant, on ne saurait passer sous silence l'optimisme de Lamontagne, qui célèbre le dynamisme de la littérature québécoise à chacune des pages de son ouvrage. C'est à se demander si l'étude n'est pas un prétexte, certes louable, pour faire la promotion de la littérature québécoise. Au moins l'enthousiasme de l'auteur compense-t-il pour tous ces intellectuels qui ne calculent que les pertes dans la littérature contemporaine. D'un autre côté, si, comme le prétend Lamontagne en conclusion, la production actuelle se décline désormais sous le signe du deuil et de la remémoration, faut-il s'étonner que la critique adopte la même posture nostalgique? Il est par ailleurs ironique que, dans une monographie intitulée Le roman québécois contemporain, le propos se termine sur le constat que, avec Ying Chen, Hélène Monette et Gaétan Soucy, le roman ne "[présente] pas la même continuité, voire la même cohérence dans la rupture "(p. 257) que les œuvres du corpus. Celui qui, en lisant le titre de l'ouvrage, s'attendait (avec raison) à une contemporanéité plus fraîche sera déçu. Il convient donc de poser à nouveau la question qui coiffe ce compte rendu: où en est donc le roman québécois, aujourd'bui?

Viviane Asselin Université Laval

\section{Claude Corbo}

Les Jésuites québécois et le cours classique

après 1945.

Montréal, Septentrion,

coll. "Cahiers des Amériques ", 2004.

Dans La mémoire du cours classique. Les années aigres-douces des récits autobiographiques (2000), le professeur de science politique et exrecteur de l'UQAM Claude Corbo amorçait une réflexion sur la formation humaniste du collège classique, enrichie depuis par la publication de nombreux autres travaux sur l'histoire de l'éducation au Québec. En interrogeant les récits d'apprentissage révélés par les écrits intimes 